\title{
Phenotype-Genotype Characterization and
} Antibiotic-Resistance Correlations Among Colonizing and Infectious Methicillin-Resistant

\section{Staphylococcus aureus Recovered from Intensive Care Units}

\author{
Hanzada T Nour El-Din (D) ' \\ Aymen S Yassin (D) \\ Yasser M Ragab' \\ Abdelgawad M Hashem ${ }^{1,2}$ \\ 'Department of Microbiology and \\ Immunology, Faculty of Pharmacy, Cairo \\ University, Cairo, II562, Egypt; \\ ${ }^{2}$ Department of Microbiology and \\ Immunology, Faculty of Pharmacy, British \\ University in Egypt, El-Sherouk City, \\ Cairo, I1837, Egypt
}

\begin{abstract}
Introduction: Methicillin-resistant Staphylococcus aureus (MRSA) presents a profound hazard to public health. MRSA colonizing skin, mucous membranes, and the anterior nares without clinical symptoms is termed "colonizing MRSA". Upon manifestation of clinical symptoms, it is termed "infectious MRSA". Here, we characterize and differentiate colonizing and infectious MRSA, and analyze the phenotypic-genotypic and antibiotic susceptibility correlations.
\end{abstract}

Methodology: Clinical MRSA isolates were recovered from intensive care units (ICUs) of two major Egyptian hospitals and their biofilm formation ability was tested. Antibiograms against 16 antibiotics were determined, in addition to the minimum inhibitory concentrations (MICs) of vancomycin and linezolid. The entire collection was typed by enterobacterial repetitive intergenic consensus (ERIC)-PCR, as well as multilocus sequence typing (MLST). Representative resistance and virulence genes were detected by PCR amplification.

Results: Forty-nine isolates were confirmed as MRSA, of which 30 isolates were infectious and 19 were colonizing. Versatile resistance patterns were observed in both groups of isolates. We report a higher tendency for biofilm-formation and borderline minimum inhibitory concentrations among infectious isolates. A Positive antibiotic correlation was observed between susceptibility to protein synthesis inhibitors and cell wall inhibitors. Positive correlations were observed between isolation site and rifampicin resistance: nasal samples were enriched in rifampicin-resistant isolates, while urine and blood samples were enriched in susceptible ones. Furthermore, biofilm formation ability was slightly associated with amikacin resistance, and an association between teicoplanin resistance and the presence of the Panton-Valentine leukocidin gene was the only significant phenotype-genotype correlation observed. Finally, ERIC typing and MLST had congruent results.

Conclusion: Linezolid and vancomycin are still the most convenient choice for MRSA treatment. ERIC PCR and MLST show promising typing combination that could be easily used periodically for tracking the genotypic changes of MRSA, especially within the healthcare facilities. Several correlations were established between groups of antibiotics and the genotypes/phenotypes of the selected isolates.

Keywords: methicillin-resistant Staphylococcus aureus, MRSA carriage, MRSA colonization, multi-drug-resistant bacteria, virulence, phenotype correlations 


\section{Introduction}

Staphylococcus aureus is an ordinary member of the skin microbiota, primarily colonizing the anterior nares. $S$. aureus is an adaptable human pathogen as well and can cause diseases ranging from relatively mild infections of the skin and soft tissue to life-threatening sepsis. ${ }^{1,2}$ Being one of the ESKAPE pathogens (Enterococcus faecium, Staphylococcus aureus, Klebsiella pneumoniae, Acinetobacter baumannii, Pseudomonas aeruginosa, and Enterobacter species), it has a tremendous contribution to nosocomial infections worldwide. ${ }^{3}$ Methicillin-resistant $S$. aureus (MRSA) is defined as a group of $S$. aureus that is resistant to most beta-lactam antibiotics. Their multi resistance limits treatment options and augment the human vulnerability to their serious infections. ${ }^{4-6}$

MRSA can be classified, according to manifesting clinical symptoms, into colonizing or infectious MRSA. The presence, growth, and multiplication of the organism in one or more body sites without observable clinical symptoms or immune reaction gives rise to the colonization state. It is estimated that $20 \%$ of individuals are persistent nasal carriers of $S$. aureus, $30 \%$ are intermittent carriers, whereas about $50 \%$ are noncarriers. ${ }^{7-9}$ Meanwhile, infection is defined as a condition whereby the bacteria, after invading a body site mostly as a consequence of $S$. aureus inoculation into an open wound, are multiplying in tissue and causing clinical manifestations. ${ }^{10}$

Identification and typing of bacterial isolates are crucial for tracking their dissemination. Pulsed-field gel electrophoresis (PFGE) of genomic macro-restriction fragments is the "gold standard" for MRSA typing, ${ }^{11}$ yet, the DNA sequence-based approaches became more appealing owing to their reproducibility across the laboratories. $^{12}$ Among the techniques used are singlelocus DNA sequencing of repeat regions of the coa gene and the spa gene. The spa typing is based on sequencing of the polymorphic $\mathrm{X}$ region of the protein A gene (spa), present in all strains of $S$. aureus. ${ }^{13}$ Furthermore, the PCRbased methods such as enterobacterial repetitive intergenic consensus (ERIC-PCR) and multi-locus sequence typing (MLST) are frequently used as well. The two techniques are widely used as they are both relatively simple and straightforward in with ERIC-PCR having the additional advantage of being relatively efficient economically. ${ }^{14}$ In ERIC -PCR, repetitive units of DNA are amplified by a single primer which yields a DNA fingerprint. This approach allows tracking the spread of certain strains and may expedite the analysis of transmission and support in infection control measures. ${ }^{15}$ Meanwhile, in MLST characterizing bacterial species is based on single nucleotide variation, usually using the internal sequence fragments of seven house-keeping genes. ${ }^{16,17}$

In the present study, our aim is to characterize and differentiate both colonizing and infectious MRSA isolates, collected from ICU patients, and determine their genetic relatedness using biochemical, molecular, and typing techniques.

\section{Materials and Methods Ethical Approval}

The study was approved by the Faculty of Pharmacy, Cairo University Safety and Occupational Health Committee. Approval Number (MI357). The committee approved that no consent was needed for collection of the MRSA isolates. All isolates were originally biobanked at the hospitals from which they were collected. There was no direct or indirect contact with any patient and consequently no informed consent was required.

\section{Sample Collection, Laboratory Processing and Characterization}

One hundred clinical isolates of known sample origins were recovered from the stocks in the clinical laboratories of two major Egyptian hospitals between 2014 and 2017. The isolates were retrieved from patients with no colonizing or infectious MRSA at the admission time but developed the colonization or infection while hospitalized. All isolates were cultivated on mannitol salt agar (MSA) selective medium for Staphylococcus aureus (Difco, USA) and then cultured on ORSAB chromogenic media (Oxoid, UK) to select for MRSA. Culture media identification was followed by conventional laboratory approaches including Gram stain, catalase production, oxidation/fermentation pattern, coagulase, DNase and gelatinase testing. Finally, confirmation was carried out using API Staph-test (Bio-Merieux, France) and dry spot staphytect plus kit (Oxoid, UK).

\section{Biofilm Formation Assay (Crystal Violet-Based Method)}

All isolates were screened for their biofilm formation ability in 96-well plates using the crystal violet-based assay. ${ }^{18}$ Briefly, $18 \mathrm{~h}$ trypticase soya broth (TSB) cultures of tested staphylococci isolates were normalized to an 
optical density (OD) of one at $600 \mathrm{~nm}$, and then diluted 1:100 with fresh TSB. Volumes of $200 \mu \mathrm{L}$ of the diluted cultures were used to fill the wells of a 96-well flatbottomed plates which were incubated for $24 \mathrm{~h}$ at $37{ }^{\circ} \mathrm{C}$. Non-inoculated TSB was included as a blank (negative control) and $S$. aureus strains US300 was used as a biofilm forming positive control. ${ }^{19}$ The biofilms were washed three times with PBS and left to dry overnight after discarding the growth medium and the unattached cells. Crystal violet $(0.4 \% \mathrm{w} / \mathrm{v})$ was used to stain the adherent cells at room temperature for $15 \mathrm{~min}$. Then, wells were washed, $150 \mu \mathrm{L}$ of absolute ethanol was added, and absorbance at $\mathrm{OD}_{595}$ was recorded. ${ }^{18}$ An isolate was classified as strong biofilm former if the $\mathrm{OD}_{595}$ was more than 0.24 , moderate $(0.12-0.24)$ and weak (nonbiofilm forming) if $\mathrm{OD}_{595}$ was less than $0.12 .^{20,21}$

\section{Antibiogram and Minimum Inhibitory Concentration Determination}

Antimicrobial agents' choice: Sixteen antibiotics were selected belonging to four different groups according to their mechanisms of action. The antibiotic groups (and content in $\mu$ g per disc) were as follows: Group I: protein synthesis inhibitors; doxycycline $30 \mu \mathrm{g}$, amikacin $30 \mu \mathrm{g}$, clindamycin $2 \mu \mathrm{g}$, erythromycin $15 \mu \mathrm{g}$, fusidic acid $10 \mu \mathrm{g}$, quinupristin-dalfopristin $15 \mu \mathrm{g}$, mupirocin $5 \mu \mathrm{g}$ and linezolid $30 \mu \mathrm{g}$. Group II: cell wall synthesis inhibitors; eg, cefoxitin $30 \mu \mathrm{g}$, teicoplanin $30 \mu \mathrm{g}$, amoxicillin-clavulanic $30 \mu \mathrm{g}$, meropenem $10 \mu \mathrm{g}$ and vancomycin $30 \mu \mathrm{g}$. Group III: DNA/RNA synthesis inhibitors; eg, levofloxacin $5 \mu \mathrm{g}$, eg, rifampicin $5 \mu \mathrm{g}$. Group IV: metabolic pathway inhibitors; eg, Sulfamethoxazole-trimethoprim $25 \mu \mathrm{g}$. All antibiotic discs were purchased from (Bioanaylase, Turkey).

The susceptibility of MRSA isolates to different antimicrobial agents was measured in vitro by disc diffusion method on Mueller-Hinton agar plates according to KirbyBauer method. ${ }^{22}$ Isolates were classified into susceptible, intermediate or resistant according to the Clinical and Laboratory Standards Institute (CLSI) guidelines. ${ }^{23}$

MIC against the two antibiotics vancomycin and linezolid was performed using the two-fold broth microdilution method. MRSA isolates of MIC $\leq 4 \mu \mathrm{g} / \mathrm{mL}$ to linezolid were considered susceptible, while those of MICs $\leq 2 \mu \mathrm{g} / \mathrm{mL}$ to vancomycin were considered to be sensitive according to the Clinical and Laboratory Standards Institute (CLSI) guidelines. ${ }^{23}$ The MIC against the two antibiotics was evaluated after $24 \mathrm{~h}$ incubation at
$37{ }^{\circ} \mathrm{C}$ and scored visually as the lowest concentration that completely inhibits bacterial growth. The MIC was determined in triplicate for each isolate and MRSA USA300 strain was used as quality control strain. Wells with culture media only were used to ensure sterility and wells with media and organism were used as a positive control.

\section{Molecular Typing of Isolates}

DNA from all tested strains was extracted using QIAamp DNA mini kit (Qiagen, Germany) according to the manufacturer's instructions and was subsequently used in PCR reactions. Exact concentration of the DNA extracted from the cells and its purity were determined using a nanodrop device (Implen, CA, USA).

\section{Detection of Multidrug Resistance and Virulence Determinants Using PCR}

A total of 8 colonizing and 12 infectious isolates were randomly chosen to be tested for two resistance genes: mecA gene (responsible for beta-lactam resistance) and cfr gene (responsible for antibiotic resistance to linezolid), in addition to the virulence gene: Panton-Valentine leukocidin toxin gene ( $p v l$ gene). MRSA USA300 was used as a positive quality control strain for $m e c A$ gene and negative control with no DNA was always included in all reactions. PPCR amplifications were carried out in a final reaction volume of $25 \mu \mathrm{L}$ using master mix to which 10 pmoles of each primer, 0.5 units of taq polymerase, 40-200 ng DNA (according to the clinical isolate used) and water up to $25 \mu \mathrm{L}$ were added. PCR conditions were initial denaturation at $95^{\circ} \mathrm{C}$ for 2 minutes, followed by 30 cycles of denaturation $95^{\circ} \mathrm{C} 30 \mathrm{sec}$, annealing at $52{ }^{\circ} \mathrm{C}-58{ }^{\circ} \mathrm{C}$ (the exact temperature was adjusted for the different primer pair) for $30 \mathrm{sec}$, extension at $72{ }^{\circ} \mathrm{C}$ for $30-60 \mathrm{sec}$ and final extension at $72{ }^{\circ} \mathrm{C}$ for $5-10 \mathrm{~min}$.

\section{ERIC-PCR Fingerprinting}

PCR reactions for enterobacterial repetitive intergenic consensus (ERIC) polymerase chain reaction (PCR) were done using master mix to which 10 pmoles primer, 1 unit of taq polymerase, 1 ng DNA, and water were added to $25 \mu \mathrm{L}$. PCR conditions were initial denaturation at $95^{\circ} \mathrm{C}$ for $2-5$ minutes followed by 30 cycles of denaturation $95^{\circ} \mathrm{C} 1 \mathrm{~min}$, annealing at $25^{\circ} \mathrm{C}-35^{\circ} \mathrm{C}$ for $1-5$ min, extension at $72^{\circ} \mathrm{C}$ for $4-5 \mathrm{~min}$ and final extension at $72^{\circ} \mathrm{C}$ for $8 \mathrm{~min}$. The PCR patterns were visually compared, and a binary value ( 0 or 1 ) designating the absence 
or presence of each band was assigned to each pattern. Cluster analysis was performed by ExPASy UPGMA, and dendrograms were visualized using FigTree v1.4.4. ${ }^{24}$

\section{Multi Locus Sequencing Typing (MLST)}

Based on ERIC1 typing, three colonizing isolates (11, 15 and 19) of no close clone types were selected as well as three highly close infectious isolates (26, 34 and 37) for MLST. Seven housekeeping genes designated for $S$. aureus: carbamate kinase ( $\operatorname{arcC})$, shikimate dehydrogenase ( $a r o E)$, glycerol kinase $(g l p F)$, guanylate kinase $(g m k)$, triosephosphate isomerase (tpi), acetyl coenzyme A acetyltransferase (yqiL) and phosphate acetyltransferase ( $p t a)$ were selected as directed. The PCR mixture was done as mentioned in ERIC analysis. Negative PCR controls were carried out with each primer set using sterile DNA-free water as template. The PCR cycling parameters for all housekeeping genes were as follows: $95^{\circ} \mathrm{C}$ for $2 \mathrm{~min}, 30 \times$ cycles of $95^{\circ} \mathrm{C}$ for $30 \mathrm{sec}, 55^{\circ} \mathrm{C}$ for $30 \mathrm{sec}$ and $72^{\circ} \mathrm{C}$ for $30 \mathrm{sec}$ and $72^{\circ} \mathrm{C}$ for 5 min. Purified PCR products were sent for Sanger Sequencing at Macrogen labs (Cairo, Egypt) using ABI PRISM BigDye terminator cycle sequence system (Applied Biosystems, Carlsbad, CA, USA). The sequences of the seven housekeeping genes were retrieved from MLST database (https://pubmlst.org/multilocus-sequence-typing/) and compared to our sequenced products.

Detection of all amplified genes was done by agarose gel electrophoresis using $1 \% \mathrm{~W} / \mathrm{V}$ gel in $1 \%$ TAE buffer except for ERIC reactions $(1.5 \% \mathrm{~W} / \mathrm{V}$ gel in $1 \%$ TAE buffer). In case needed, PCR products were purified using Qiaquick PCR purification kit (Qiagen, Germany) according to the manufacturer's instructions to be sequenced. All primers used in the study are listed in Table 1.

\section{Statistical Analysis}

Potential associations between all possible pairs of phenotypes (isolate type, source, specimen: blood or nasal, biofilm ability, and antibiogram) and tested genes were tested by Fisher's exact test. In addition, the potential correlation between many of these variables (those that are either numeric or that could be converted into pseudo-numeric values) was tested by Pearson's correlation and represented as a correlation plot, highlighting the significant associations, as well as others that are less obvious. For all statistical analyses, $p$-values $<0.05$ were considered significant. All analyses were carried out in R-Studio version 1.2.1335. Specific R package that was used in statistical analysis or data visualization is corrplot. All other plots were generated using GraphPad Prism (v6) (GraphPad, California, CA, USA).

\section{Results}

\section{Laboratory Identification, Biochemical Testing, and Isolates Differentiation}

Out of the 100 screened isolates, 85 isolates were identified as $S$. aureus by their growth pattern and yellow color formation on mannitol salt agar. Growing the isolates on ORSAB medium identified 49 isolates as MRSA, as they showed blue colonies. Microscopical examination of the 49 MRSA isolates showed Gram-positive cocci and conventional biochemical laboratory testing followed and its results were typical for MRSA. API was used as a final confirmation for the identity of the isolates.

Clinical isolates were classified according to symptom manifestation into colonizing or infectious MRSA..$^{10,25}$ Out of the 49 confirmed MRSA isolates, 30 were considered as infectious MRSA (with symptom manifestation on the patient) and 19 were colonizing (bacteria present with no symptoms)

Table I List of Primers Used in the Current Study and Predicted Size of PCR Products

\begin{tabular}{|c|c|c|c|c|}
\hline Gene & Forward Primer (5' to $\left.3^{\prime}\right)$ & Reverse Primer (5' to $\left.3^{\prime}\right)$ & Size & Reference \\
\hline $\operatorname{arcC}$ & TTG ATT CAC CAG CGC GTA TTG TC & AGG TAT CTG CTT CAA TCA GCG & 456bp & (Enright, et al, 2000) \\
\hline $\operatorname{aroE}$ & ATC GGA AAT CCT ATT TCA CAT TC & GGT GTT GTA TTA ATA ACG ATA TC & $456 \mathrm{bp}$ & (Enright, et al, 2000) \\
\hline$c f r$ & GACTTTCGGCACCGGTAAT & CAGTAGTCCATTCATATTTG & $745 b p$ & (Shore, et al, 20I0) \\
\hline$g l p F$ & CTA GGA ACT GCA ATC TTA ATC C & TGG TAA AAT CGC ATG TCC AAT TC & $465 \mathrm{bp}$ & (Enright, et al, 2000) \\
\hline gmk & ATC GTT TTA TCG GGA CCA TC & TCA TTA ACT ACA ACG TAA TCG TA & 430bp & (Enright, et al, 2000) \\
\hline Luk-pvl & ATCATTAGGTAAAATGTCTGGACATGATCCA & GCATCAAGTGTATTGGATAGCAAAAGC & 430bp & (Zhang, et al, 2004) \\
\hline $\operatorname{mec} A$ & GTAGAAATGACTGAACGTCCGATAA & CCAATTCCACATTGTTTCGGTCTAA & $310 \mathrm{bp}$ & (Zhang, et al, 2004) \\
\hline pta & GTT AAA ATC GTA TTA CCT GAA GG & GAC CCT TTT GTT GAA AAG CTT AA & $475 b p$ & (Enright, et al, 2000) \\
\hline$t p i$ & TCGTTCATTCTGAACGTCGTGAA & TTTGCACCTTCTAACAATTGTAC & $402 \mathrm{bp}$ & (Enright, et al, 2000) \\
\hline yqiL & CAGCATACAGGACACCTATTGGC & CGTTGAGGAATCGATACTGGAAC & $516 \mathrm{bp}$ & (Enright, et al, 2000) \\
\hline ERIC I & ATGTAAGCTCCTGGGGATTCAC & & & (Candan, et al, 20l3) \\
\hline
\end{tabular}


MRSA. Infectious isolates were originally clinical samples of the following sources: urine $(20 \%)$, blood $(23 \%)$, sputum $(10 \%)$, pus $(9 \%)$, intratracheal intubation $(4 \%)$, in addition to unknown sites (34\%). For further statistical analysis, pus and intratracheal samples were combined. Colonizing isolates originally were clinical samples from the groin (63\%) and nasal area $(37 \%)$ areas as localized body sites (Figure 1$)$.

\section{Biofilm Formation Ability}

The 49 isolates were classified into weak (Non-biofilm forming) or moderate or strong (Biofilm forming). It was noted that infectious isolates had a higher tendency for biofilm formation with a percentage of biofilm forming isolates of $76.7 \%$ when compared to the colonizing isolates that had a percentage of $52.6 \%$ (Figure 2 and Supplementary Table 1).

\section{Vancomycin and Linezolid MICs Patterns in MRSA from Different Isolate Types}

To investigate any differences in patterns of vancomycin and linezolid MICs for MRSA isolates recovered from different sources, we compared MICs. The MIC breakpoint of vancomycin was $\geq 2 \mu \mathrm{g} / \mathrm{mL}$, while for linezolid it was $\geq 4 \mu \mathrm{g} / \mathrm{mL}$ as per CLSI guidelines. ${ }^{23}$ No vancomycin or linezolid resistant MRSA strains were detected. Borderline MIC of $2 \mu \mathrm{g} / \mathrm{mL}$ for vancomycin was shown in three infectious strains and was not noted in any colonizing isolate. Most of the isolates showed an MIC of 0.5 $\mu \mathrm{g} / \mathrm{mL}$ towards vancomycin. Linezolid MICs of the infectious isolates showed the following results: seven isolates had a borderline MIC of $4 \mu \mathrm{g} / \mathrm{mL}$ and the remaining 23 strains had an MIC of $2 \mu \mathrm{g} / \mathrm{mL}$. On the other hand, colonizing isolates had only one borderline isolate, eight
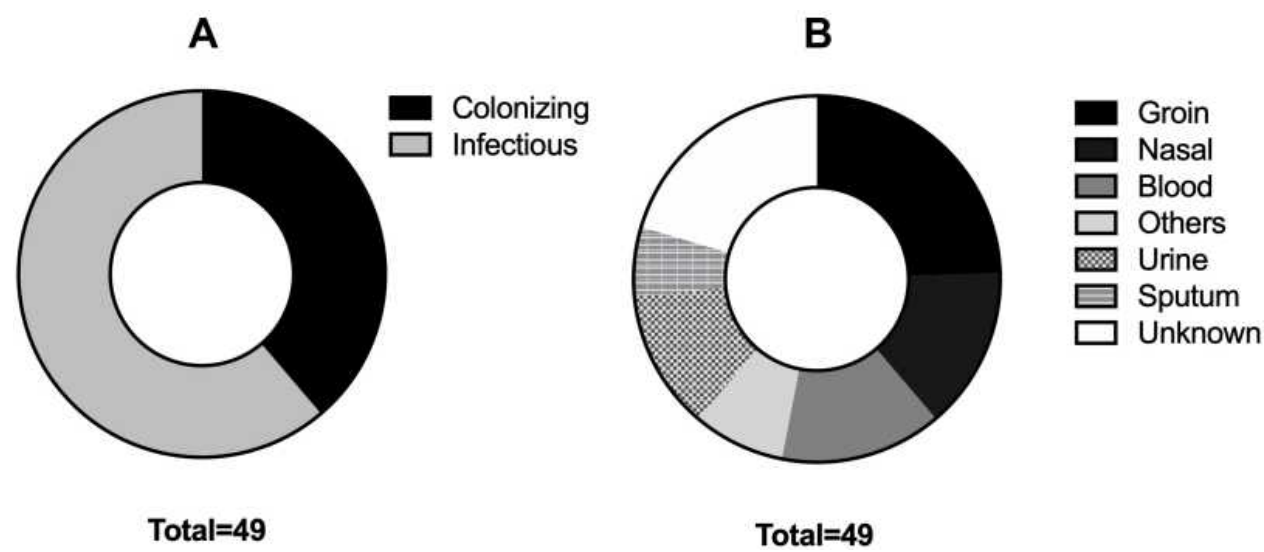

Figure I Distribution of isolates according to symptoms manifestation. Pie charts showing $(\mathbf{A})$ the relative distribution of colonizing and infectious isolates, as well as (B) the detailed sites of isolation of both types.

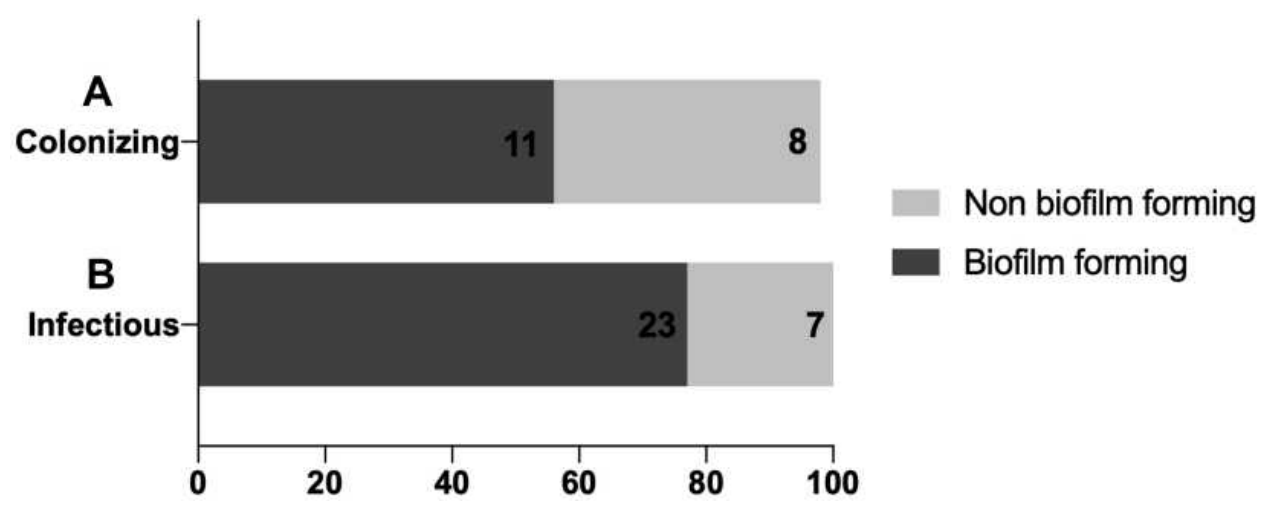

Figure 2 Distribution of biofilm formation ability among both colonizing and infectious isolates. (A) A stacked bar plot indicating the percentage of colonizing isolates with biofilm and non biofilm forming ability. (B) A stacked bar plot indicating the percentage of infectious isolates with biofilm and non biofilm forming ability. The $X$-axis represents the percentage of either biofilm forming isolates (dark grey bars) or non biofilm forming isolates (light grey bar). The number written inside each bar represents the number of isolates constituting the final percentage. 
isolates with an MIC of $2 \mu \mathrm{g} / \mathrm{mL}$ and ten isolates with an MIC of $1 \mu \mathrm{g} / \mathrm{mL}$ (Figure 3).

\section{In vitro Antibiotic Susceptibility Profile of the Isolates}

Using the disc diffusion method, the whole collection of 49 isolates were tested for their antibiotic susceptibility against 16 different antibiotics belonging to various classes. Versatile patterns of resistance and susceptibility were observed among both groups of isolates (Figure 4). Both infectious and colonizing groups exhibited full sensitivity towards linezolid, quinupristin-dalfopristin, cefoxitin and vancomycin. Almost an equal resistance pattern was observed in both groups towards amikacin, meropenem, erythromycin, clindamycin and amoxicillinclavulanic acid. Colonizing isolates had a higher resistance pattern towards fusidic acid, rifampicin, and sulfamethoxazole-trimethoprim and erythromycin compared to infectious isolates. Colonizing isolates had higher sensitivity towards doxycycline as well, while infectious isolates showed higher sensitivity towards levofloxacin. Finally, two colonizing isolates showed resistance to teicoplanin with a zone diameter of $10 \mathrm{~mm}$, while no infectious isolates were teicoplanin resistant.

\section{Detection of Resistance and Virulence Genes}

All isolates were tested for the presence of mecA gene (responsible for beta-lactam resistance). All colonizing isolates were positive for the tested gene except one colonizing isolate. Meanwhile, all the infectious isolates tested positive for the tested gene. All tested isolates were negative for $c f r$ gene, responsible for antibiotic resistance to various groups of antibiotics including oxazolidinones, lincosamides, streptogramin A, phenicols and pleuromutilins. Two colonizing and two infectious isolates tested positive for the Panton-Valentine leukocidin toxin ( $p v l$ gene), a prophage encoded bicomponent pore-forming protein associated with primary skin infections and necrotizing pneumonia.

\section{Molecular Typing ERIC Typing}

The entire isolate collection was subjected to molecular typing by ERIC-PCR. The profiles obtained had amplified DNA fragments that extended in size from 150 to $1000 \mathrm{bp}$. According to these band pattern data, a dendrogram was generated using the Unweighted Pair Group Method with Arithmetic Mean (UPGMA) and visualized with Figtree (Figure 5). ERIC analysis revealed 19 distinct patterns of MRSA isolates with similarity $>80 \%$. According to the generated dendrogram, isolates (01 and 40), (37, 26 and $30),(06,15$ and 03), (20 and 24), (22 and 21), (46 and 45), $(27,33$ and 04$)$ and $(10,25$ and 16) showed high similarity, signifying that those isolates constitute a clonal lineage. The whole isolates collection was classified, based on ERIC typing, into seven pure colonizing groups, seven pure infectious groups and five mixed combinations of both colonizing and infectious isolates.

\section{Multi-Locus Sequence Typing}

Sequencing of the seven housekeeping genes showed that the three chosen colonizing isolates had high variability within each other and were of no closeness in the seven detected genes. The seven HKG were assigned to different alleles by MLST and to different strains by BLAST servers (Table 2), one colonizing isolate came from the $S$. aureus clonal lineage $\mathrm{CC} 45$, the second isolate belonged to $\mathrm{CC} 15$ that was deposited from a nasal swab in Norway and the last matched the S. aureus FORC_001 strain. Meanwhile, the three infectious isolates showed high similarity towards several of the HKG using both BLAST and MLST servers (Table 2) and all belonged, with minimum four or more gene hits, to clonal complex CC8.

\section{Antibiotic Correlations}

It was expected that the isolates may have similar resistance patterns towards antibiotics of the same or close chemical classes. To test this hypothesis, we investigated the correlation matrix generated (Figure 6) to find out the relationships between different tested antibiotics, with exclusion of linezolid and vancomycin, to which all isolates were sensitive. This analysis indicated positive and negative correlations depending on the groups of antibiotics tested. It was noted that protein synthesis inhibitors were correlated together and were also correlated to cell wall synthesis inhibitors. For example, positive correlation was detected between amikacin (AMK) and both meropenem (MEM) and doxycycline $(\mathrm{DOX})$ (correlation coefficient $=0.589$ and 0.6, respectively). Clindamycin (CLX) was strongly correlated to meropenem (MEM), amikacin (AMK), doxycycline (DOX) and erythromycin (ENX) (correlation coefficient $=0.46,0.5,0.464$ and 0.515 , respectively). 
A

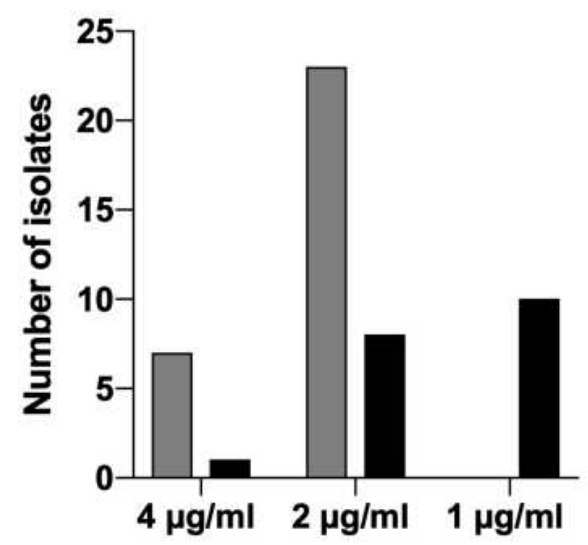

Linezolid MIC
B

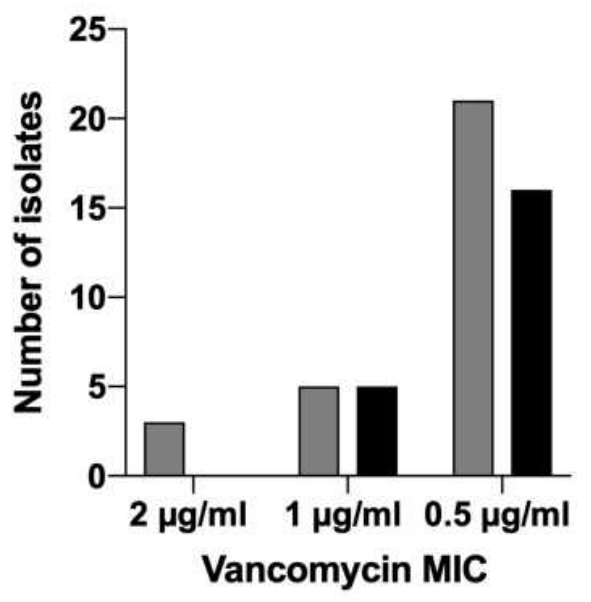

Figure 3 Minimum inhibitory concentration patterns. (A) Comparison of linezolid MICs of both colonizing and infectious isolates. (B) Comparison of vancomycin MICs of both colonizing and infectious isolates. Grey bars represent colonizing isolates and black bars representing infectious ones.

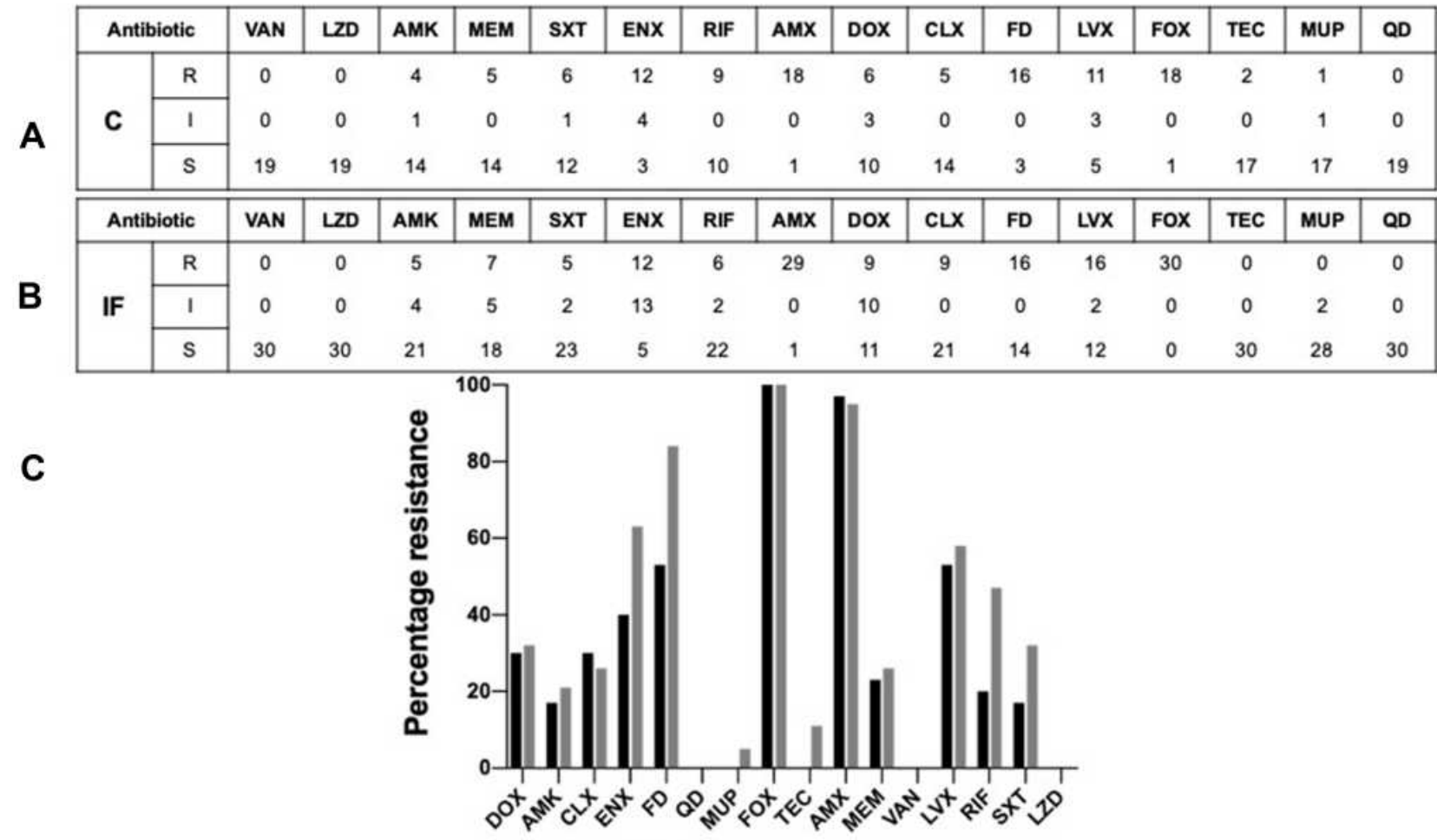

\section{Colonizing Infectious}

Figure 4 Antibiogram of the tested colonizing and infectious isolates. (A) Colonizing isolates antibiogram results tabular representation towards the 16 tested antibiotics. (B) Infectious isolates antibiogram results tabular representation towards the 16 tested antibiotics; classification was done as follows "resistant (R), intermediate (I) and sensitive (S)". (C) Bar charts showing the percentages of resistant isolates towards the 16 different antibiotics used. The black bars represent the infectious isolates, and the grey bars represent the colonizing isolates.

Abbreviations: VAN, vancomycin; LZD, linezolid; AMK, amikacin; MEM, meropenem; SXT, trimethoprim/sulfamethoxazole; ENX, erythromycin; RIF, rifampicin; AMX, amoxicillin clavulanic; DOX, doxycycline; CLX, clindamycin; FD, fusidic; LVX, levofloxacin; MUP, mupirocin; FOX, cefoxitin; TEC, teicoplanin; QD, quinupristin-dalfopristin. 


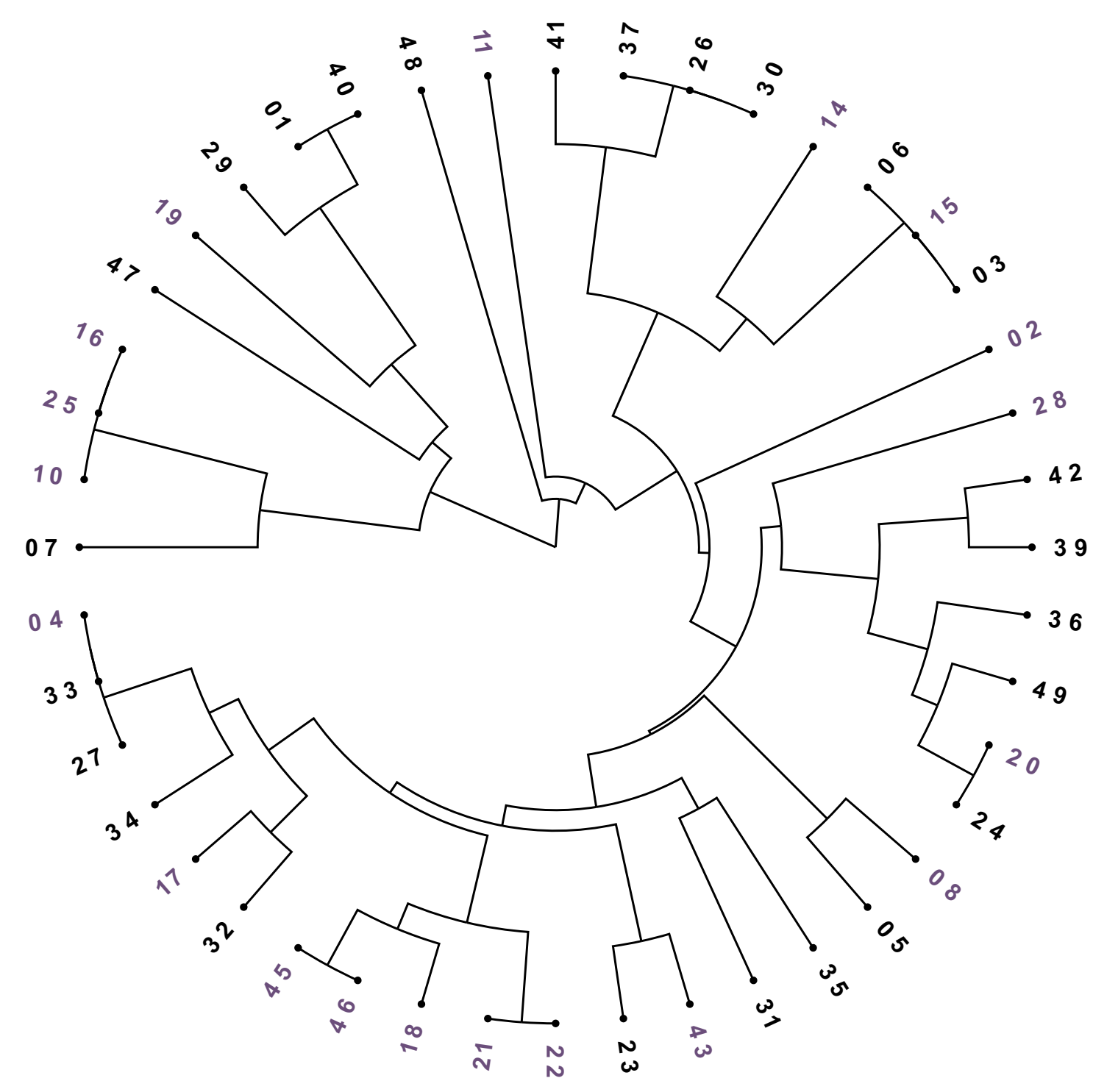

6.0

Figure 5 ERIC-PCR analysis of the tested MRSA isolates. Unweighted pair group method using arithmetic overage algorithm (UPGMA) clustering method, showing the genetic similarity among MRSA isolates by enterobacterial repetitive intergenic consensus (ERIC) genotyping. Radial dendrogram, in decreasing nodes order, was generated with FigTree vl.4.4. Blue labels represent the colonizing isolates and black labels represent the infectious isolates.

On the other hand, the only negative correlation was between trimethoprim/sulfamethoxazole (SXT) and doxycycline (DOX) (correlation coefficient $=-0.4$, Fisher's Exact Test $p$-value $=0.03$ ).

Meropenem (MEM) showed three more associations with fusidic (FD), doxycycline (DOX) and levofloxacin
(LVX), Fisher's Exact Test $p$-value $=0.044,0.04$ and 0.012. Levofloxacin (LVX) was strongly correlated to clindamycin (CLX) (correlation coefficient $=0.544$, Fisher's Exact Test $p$-value $=0.00049)$. Finally, erythromycin (ENX) and rifampicin (RIF) were found to be correlated (Fisher's Exact Test $p$-value $=0.01$ ). 
Table 2 MLST Results Using MLST Database (Bold), BLAST, or Both (Bold and Underlined)

\begin{tabular}{|c|c|c|c|c|c|c|c|}
\hline \multirow[t]{2}{*}{ Isolates } & \multicolumn{7}{|c|}{ MLST Genes } \\
\hline & $\operatorname{arcC}$ & aroE & $g l p F$ & gmk & pta & tpi & yqiL \\
\hline Colonized-I(II) & $\begin{array}{c}\text { CA-347 } \\
99 \%\end{array}$ & No match & $\begin{array}{c}\text { CA-347 } \\
98 \%\end{array}$ & Allele 6 & $\frac{\text { Allele 14 }}{100 \%}$ & $\begin{array}{c}\text { FORC_00I, } \\
99 \%\end{array}$ & $\begin{array}{l}\text { FORC_00I, } \\
99 \% \\
\text { Allele } 2 \\
2 \text { diff }\end{array}$ \\
\hline Colonized-2 (15) & $\begin{array}{c}\text { Allele } 13 \\
100 \%\end{array}$ & $\frac{\text { Allele } 13}{100 \%}$ & $\begin{array}{c}\text { Allele } 93 \\
4 \text { diff }\end{array}$ & $\begin{array}{l}\text { Strain } 79, \\
99 \% \\
\text { Allele I } \\
\text { I diff }\end{array}$ & $\begin{array}{c}\text { Strain } 502 \mathrm{~A} \\
100 \% \\
\text { Allele } 12 \\
3 \text { diff }\end{array}$ & $\begin{array}{c}\text { Strain 79, } \\
\quad 97 \% \\
\text { Allele } 209\end{array}$ & $\begin{array}{c}\text { Allele } 13 \\
99 \%\end{array}$ \\
\hline Colonized-3 (19) & \multicolumn{6}{|c|}{ Staphylococous aureus subsp. aureus strain FORC_00I, complete genome } & \\
\hline Infectious-I (26) & $\begin{array}{c}\text { FORC_00I } \\
99 \% \\
\text { Allele } 2 \\
100 \%\end{array}$ & $\begin{array}{c}\text { Strain 27b, } \\
\text { MRSA } \\
99 \% \\
\text { Allele } 3 \\
100 \%\end{array}$ & $\begin{array}{l}\text { Strain } 79, \text { s } 10 \\
\text { genome } 98 \% \\
\text { Allele } 93 \\
3 \text { diff }\end{array}$ & No match & $\begin{array}{c}\text { Strain } 27 b \text {, } \\
\text { MRSA } \\
99 \% \\
\text { Allele } 4 \\
100 \%\end{array}$ & No match & $\begin{array}{c}\text { Strain 27b, } \\
\text { MRSA } \\
99 \% \\
\text { Allele } 3 \\
100 \%\end{array}$ \\
\hline Infectious-2 (34) & $\begin{array}{c}\text { S. aureus strain } \\
\text { FORC_00I 100\% } \\
\text { Allele } 2 \\
100 \%\end{array}$ & $\begin{array}{c}\text { Strain 27b } \\
\text { MRSA } \\
99 \% \\
\text { Allele } 3 \\
99 \%\end{array}$ & $\begin{array}{c}\text { Strain } 79 \\
97 \% \\
\text { Allele } 93 \\
3 \text { diff }\end{array}$ & $\begin{array}{c}\text { Strain } 27 \mathrm{~b} \\
\text { MRSA 100\% } \\
\text { Allele I } \\
100 \%\end{array}$ & $\begin{array}{c}\text { Strain } 27 \mathrm{~b} \text { MRSA } \\
100 \% \\
\text { Allele } 4 \\
100 \%\end{array}$ & $\begin{array}{c}\text { Strain 27b MRSA } \\
97 \% \\
\text { Allele } 154 \\
100 \%\end{array}$ & $\begin{array}{c}\text { Strain } 27 \mathrm{~b} \text { MRSA } \\
99 \% \\
\text { Allele } 3 \\
100 \%\end{array}$ \\
\hline Infectious-3 (37) & $\begin{array}{c}\text { S. aureus strain } \\
\text { FORC_00I 100\% } \\
\text { Allele } 2 \\
100 \%\end{array}$ & $\begin{array}{c}\text { Strain 27b } \\
\text { MRSA } \\
99 \%\end{array}$ & $\begin{array}{l}\text { Strain KIBGE- } \\
\text { MB99 99\% } \\
\text { Allele } 93 \\
8 \text { diff }\end{array}$ & $\begin{array}{c}\text { Strain } 79 \text {, } \\
100 \% \\
\text { Allele I } \\
100 \%\end{array}$ & $\begin{array}{c}\text { Strain 27b MRSA } \\
100 \% \\
\text { Allele } 4 \\
100 \%\end{array}$ & No match & $\begin{array}{c}\text { Strain 27b MRSA } \\
99 \% \\
\text { Allele } 3 \\
100 \%\end{array}$ \\
\hline
\end{tabular}

\section{Phenotype-Antibiotic Correlations}

Nasal isolates, in particular, were correlated with rifampicin (RF) (correlation coefficient $=0.586$ and Fisher's Exact test $p$-value 0.002). Blood isolates showed no significant correlations. Isolate type had two significant association with two tested phenotypes. The first one was the association with fusidic acid (FD) (Fisher's Exact test $p$-value 0.034). The second one was with linezolid MIC (Fisher's Exact test $p$-value 0.0005). The source of the samples (Groin, nasal, blood, sputum, urine, other and unknown) had three significant associations. The first one was with rifampicin (RF) (Fisher's Exact test $p$-value 0.013). For example, six out of seven nasal isolates were resistant to rifampicin while all urine samples were sensitive. The second correlation was with both linezolid MIC and linezolid status (Fisher's Exact test $p$-value 0.0005 and 0.0374 , respectively), as seven infectious isolates had borderline MIC towards linezolid. Finally, biofilm formation ability was slightly associated with amikacin (AMK) (Fisher's Exact test $p$-value 0.043).

\section{Phenotype-Genotype Correlations}

The only significant association between one of the measured phenotypes and a gene detected by PCR was the association between teicoplanin resistance (TEC) and the presence of the Panton-Valentine leukocidin $(p v l)$ gene (Fisher's Exact test $p$-value $=0.038$ ).

\section{Discussion}

Infections caused by MRSA are harder and more financially burdening to treat than infections caused by methicillin-sensitive Staphylococcus aureus strains. ${ }^{26,27}$ Colonization with MRSA has been suggested to intensify the hazard of developing subsequent infections by providing a reservoir for the pathogen and such colonization threatens both the carrier and the community. ${ }^{28,29}$

The present study aimed to characterize both colonizing and infectious MRSA and analyze their phenotypicgenotypic variations. A total of 49 MRSA isolates (30 infectious and 19 colonizing isolates) were properly identified. Biofilm formation ability, a bacterial survival 


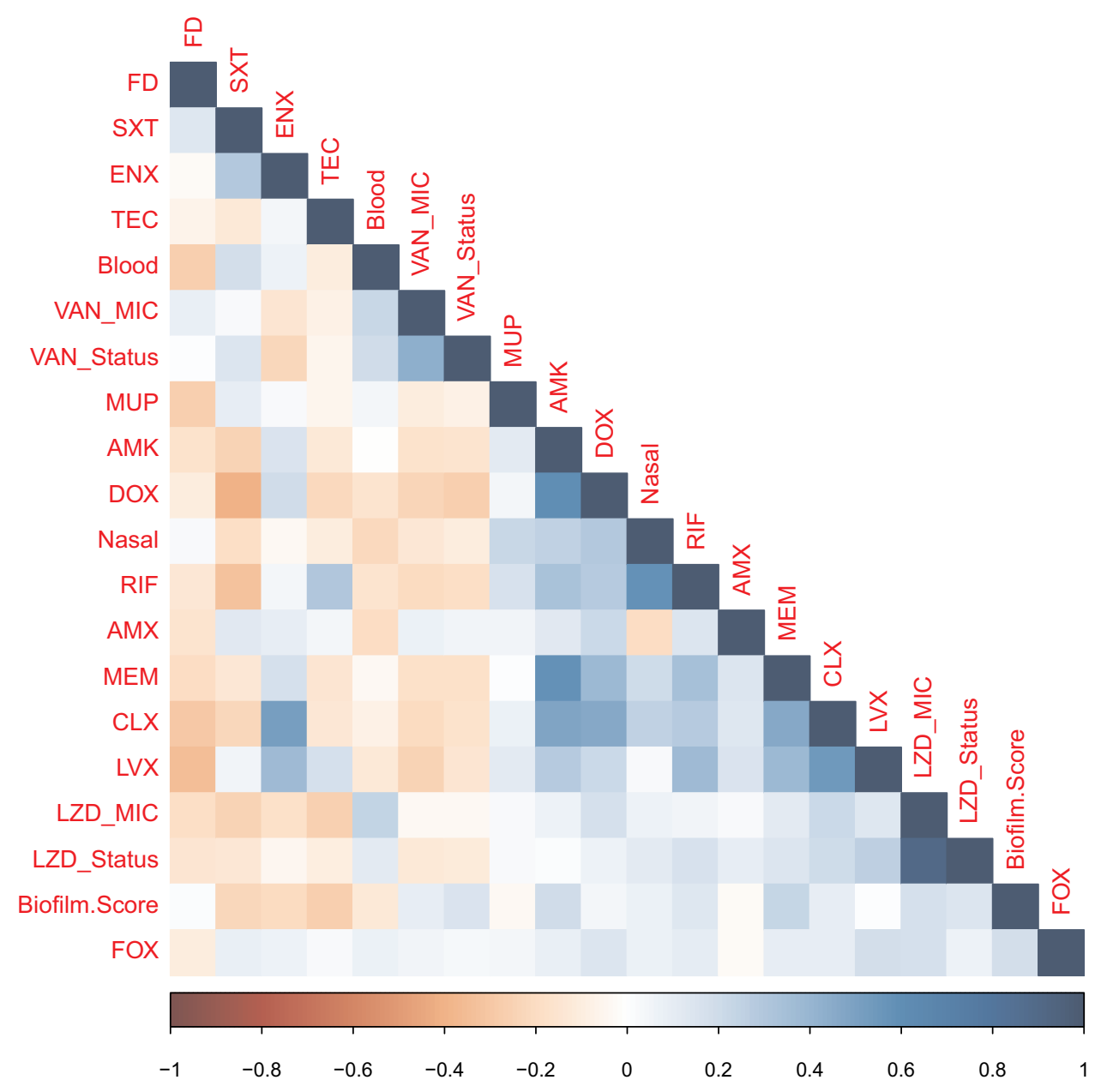

Figure 6 Phenotype-genotype correlation. Phenotype-genotype correlation matrix. A colored matrix representing the correlations between all possible pairs of phenotypes (isolate type, source, specimen, biofilm ability, and antibiogram) and tested genes of the whole isolates collection. Vancomycin and linezolid were not included as all isolates were sensitive to them. The color represents Pearson's correlation coefficient and its intensity represents the coefficient's value (shades of blue are positive correlations and shades of orange-brown are negative correlations). Figure labels for antibiotics; figure labels for biofilm. Score; strong biofilm forming=3, moderate biofilm forming=2, weak biofilm forming=3. Figure labels for minimum inhibitory concentration (MIC); LZD_Status= borderline or not borderline MIC and LZD_MIC=I, 2 and $4 \mu \mathrm{g} / \mathrm{mL}$. The figure was generated using R-software.

Abbreviations: LZD, linezolid; AMK, amikacin; MEM, meropenem; SXT, trimethoprim sulfamethoxazole; ENX, erythromycin; RIF, rifampicin; AMX, amoxicillin clavulanic; DOX, doxycycline; CLX, clindamycin; FD, fusidic; LVX, levofloxacin; MUP, mupirocin; FOX, cefoxitin; TEC, teicoplanin; QD, quinupristin-dalfopristin.

strategy, ${ }^{2}$ was tested and our results revealed that infectious isolates have a higher biofilm formation ability compared to colonizing isolates. These results indicate that infectious MRSA can persist more in clinical settings, elevating their chances of increased resistance and virulence. It was noted that colonizing nasal isolates had a higher biofilm formation ability in comparison to groin isolates. This is a logical finding, as nares is the main ecological niche of colonizing isolates. ${ }^{30}$

Antibiogram analysis revealed that both colonizing and infectious isolates exhibited almost equal resistance to amikacin, amoxicillin-clavulanic acid and clindamycin. These results were expected as those antibiotics belonged to classes to which MRSA strains were resistant. ${ }^{31,32}$
Moreover, a high number of erythromycin-resistant and intermediate isolates was observed among both colonizing and infectious samples. The high resistance pattern towards both clindamycin and erythromycin could be attributed to the presence of erm(A) gene. ${ }^{33}$ This was previously reported in a study conducted in a Belgian acute-care hospital that investigated the macrolide/lincosamides (ML) resistance. MRSA strains resistant to macrolides or macrolides/lincosamides harbored the gene $\operatorname{erm}(\mathrm{A})$ in $71 \%$ of such isolates. ${ }^{34}$

Sensitivity towards antibiotics used for decolonization therapy, in the form of combinations, indicated higher resistance among colonizing isolates to sulfamethoxazoletrimethoprim and rifampicin compared to infectious isolates. In previous studies conducted in Saudi Arabia, it was 
reported that sulfamethoxazole-trimethoprim showed a low susceptibility pattern of around $33.8 \%$ and $21.1 \%^{35,36}$ or even full resistance. ${ }^{37}$ Hence, sulfamethoxazole-trimethoprim should not be used at least as an empirical treatment for MRSA isolates. Regarding rifampicin, resistance emerges easily specifically in MRSA strains. Rifampicin acts by interacting with bacterial RNA polymerase encoded by the gene $\operatorname{rpoB}$, hence, multiple mutations in this gene lead to resistance. ${ }^{38}$

Colonizing isolates also had a higher resistance pattern towards fusidic acid; a topical agent that was used for MRSA decolonization but has now been replaced by mupirocin, ${ }^{9}$ which shows lower resistance as indicated in the results. The above results reflect that the overuse of decolonizing agents, even just topically, may select for resistant members of the skin microbiota.

The possible mechanisms for fusidic acid resistance are either alteration of the drug target site, owing to mutations in fusA (encoding EF-G) or fusE (encoding ribosome protein L6). Another mechanism is protection of the drug target site through the FusB-family proteins that usually cause low levels of resistance towards fusidic acid. ${ }^{39}$ It is important to note that topical agents have the benefit of achieving high drug concentration at the site of colonization with slight risk of adverse reactions. ${ }^{40}$

Both colonizing and infectious samples were completely sensitive to linezolid, quinupristin-dalfopristin, vancomycin, cefoxitin and teicoplanin (aside from two colonizing isolates that showed resistance to teicoplanin). This sensitivity pattern makes those four antibiotics of high preference to be used in hospital settings. Teicoplanin and vancomycin are equally effective against MRSA; however, adverse effects such as nephrotoxicity, skin rash and red man syndrome are lower with teicoplanin. ${ }^{41}$ Hence, teicoplanin would make a better treatment option, specifically for patients with kidney malfunctions.

In terms of sensitivity to linezolid and vancomycin, our results agree with the study of Kishore and coworkers, ${ }^{31}$ in which no clinical linezolid resistant strains were isolated. Herein, we report infectious strains with borderline MICs against linezolid, in a process known as "MIC creep": defined as a gradual reduction in susceptibility pattern. ${ }^{42}$ On the other hand, both colonizing and infectious isolates did not show such an obvious pattern against vancomycin. Linezolid, an oxazolidinone antibiotic, is available in a rapidly absorbable oral form with no monitoring recommendations. ${ }^{43}$ Adds on, oxazolidinones do not display cross resistance with existing agents. Given all the above, we suggest that linezolid should be cautiously used to retain its efficacy and edge over other treatment options available against the increasingly resistant MRSA clinical isolates.

Several typing techniques are currently used for the characterization and differentiation of isolates. Molecular methods are often preferred over phenotypic methods owing to their high discriminatory power. ${ }^{44}$ Among the widely used typing techniques is the multilocus sequence typing (MLST) analyzing seven housekeeping genes that are pivotal to cellular functioning of microorganisms. The availability of a web-based database with all reported allelic profiles and strain types added to the ease of data comparison and ranked this technique as a global epidemiological tool. ${ }^{45}$

Enterobacterial repetitive intergenic sequences (ERICPCR) is also a simplified typing strategy for a vast number of organisms. This typing technique is highly reproducible and requires no disease-specific reagents, making it an agreeable strategy for hospital-settings. ${ }^{46}$ There is no one ideal single typing method, as every method has its merits and shortcomings as well. Hence, more than one typing method could be combined depending on the study objectives. In our study, ERIC typing classified the isolates into pure colonizing groups, pure infectious groups, and the rest were combinations from both isolates' types. The presence of "mixed" ERIC groups shows the tendency of colonizing MRSA to transform into infectious MRSA, as well as the presence of other overlapping genetic factors. Multi Locus Sequence Typing (MLST) was used to validate the correlation obtained by ERIC technique. Six isolates were selected as representative of the collection from both classes to study their pattern by MLST. The results revealed that the first colonizing isolate came from the S. aureus clonal lineage CC45, which is a prevalent colonizer of healthy individuals in northern Europe. The second isolate belonged to clonal complex CC15 that was deposited in the PubMLST as a nasal swab in Norway. The colonized sources referred to in those results matched the source from which we obtained the two isolates, as both came from colonizing patients. The third colonizing isolate belonged to the strain $S$. aureus FORC_001 originally isolated from contaminated food. Different virulence-factors encoding genes of this strain were classified, ${ }^{47}$ one of which was the luk-pvl gene which was found in our colonizing isolate and matching the MLST result. In the other three infectious isolates, MLST results were highly similar towards several of the 
HKG (Table 2) and all were closely related to CC8. Clonal complex 8 (CC8) is known to be one of the most prevalent clones throughout the world and a significant proportion of health-care-associated infections is related to strains belonging to this clonal complex. ${ }^{44,48}$

The methicillin resistance ( $m e c A$ ) gene, which encodes for the altered penicillin-binding protein (PBP2a) production, responsible for classical methicillin resistance, ${ }^{49}$ was found in all isolates except for one colonizing isolate. This may be explained by the presence of alterations in the existing PBPs. Strains with such alterations are termed moderately resistant $S$. aureus (MODSA) and are known to be less virulent than the classical MRSA. ${ }^{50}$ Another explanation is the development of a variant of the mecA gene known as the mecC gene with a genetic similarity of $70 \%,{ }^{51}$ which could explain the finding in our study. Our result was confirmed by ERIC typing that classified this isolate as a single clone, with regards to its classification, suggesting a unique genetic lineage, and providing further justification for its $m e c A$-negative PCR.

The second resistance gene was the chloramphenicolflorfenicol resistance $c f r$ gene ( $c f r$ ) that encodes a methyl transferase that affects the binding of at least five chemically unrelated antimicrobial classes: phenicols, lincosamides, oxazolidinones, pleuromutilins and streptogramin A antibiotics. ${ }^{52}$ All tested isolates were free from this gene, this came in agreement with the antibiogram results that showed all isolates $100 \%$ sensitive to linezolid. The third gene investigated was the virulence gene PantonValentine leukocidin toxin $(p v l)$ linked to skin and soft tissue infections as well as life-threatening diseases. ${ }^{53}$ The presence of $p v l$ in four of our MRSA isolates should make us more aware of the possible horizontal gene transfer to other MRSA isolates in the same hospital setting, making them more virulent and subsequently more difficult to deal with. This was proven to be correct and of high incidence in other study done in Nepal. ${ }^{54}$

Antibiotic-antibiotic correlation showed an expected strong association between antibiotics belonging to similar classes. Meanwhile, phenotypic-antibiotic correlations confirmed that nasal isolates were enriched in rifampicin resistance. Rifampicin is one of the decolonization antibiotics used in hospitals and it is usually not used alone owing to the high resistance risk of rifampicin monotherapy. ${ }^{55}$ Another association was between the isolate type and fusidic acid, as colonizing isolates in general were more resistant to this antibiotic that is used as a topical agent for $S$. aureus decolonization. Finally, phenotype-genotypic correlations delineated a positive correlation between the presence of $p v l$ gene and teicoplanin resistance. This correlation most likely poses little clinical risk, given that both factors were of low frequency among the isolates; i.e. only four isolates were $p v l$-positive and only two were teicoplanin resistant.

Taken together, the above analyses reflect the genetic diversity/heterogeneity among clinical isolates with similar phenotypes. Various assortments of resistance and virulence genotypes exist within each of the colonizing or infectious group. Such heterogeneity may be a warning sign that, through horizontal transfer of single virulence or resistance genes, a colonizing isolate may pose a risk of becoming infectious.

\section{Conclusions}

MRSA is a problematic organism posing a major health concern especially at hospitals; hence, infection control units should offer a regularly updated decolonization protocol according to the resident MRSA to prevent transformation of colonization into infection. It is noticeable that linezolid and vancomycin are still the most convenient choice for MRSA treatment owing to their high sensitivity patterns, yet linezolid should be cautiously used to avoid resistance emergence. Finally, ERIC PCR and MLST show promising typing combination that could be used periodically for genotyping of MRSA isolates from inpatients to aid in the correct treatment.

\section{Acknowledgment}

We would like to thank the late professor Dr. Magdy Ali Amin, Professor of Microbiology and Immunology, Faculty of Pharmacy, Cairo University for his guidance and advice in this work. We are immensely grateful for Dr. Ramy Karam Aziz, Professor of Microbiology and Immunology, Faculty of Pharmacy, Cairo University and former Head of Microbiology and Immunology department for his assistance with the statistical analysis and correlation determination. Finally, we would like to thank Dr. Tarek Salman, Professor of Microbiology and Immunology, Faculty of Pharmacy, Al-Azhar University and Dr. Abdel Bary Bernce, Faculty of Veterinary Medicine, Cairo University, for their constant support through this work.

\section{Author Contributions}

All authors made a significant contribution to the work reported, whether that is in the conception, study design, execution, acquisition of data, analysis and interpretation, 
or in all these areas; took part in drafting, revising or critically reviewing the article; gave final approval of the version to be published; have agreed on the journal to which the article has been submitted; and agree to be accountable for all aspects of the work.

\section{Funding}

No funding was received for this research from funding agencies in the public, commercial, or not-for-profit sectors. This work was mainly self-funded by the authors and in part through the Cairo University research funding system for assistant lecturers.

\section{Disclosure}

The authors have declared no conflicts of interest.

\section{References}

1. Dulon M, Haamann F, Peters C, Schablon A, Nienhaus A. MRSA prevalence in European healthcare settings: a review. BMC Infect Dis. 2011;11(1):138. doi:10.1186/1471-2334-11-138

2. Geoghegan JA, Corrigan RM, Gruszka DT, et al. Role of surface protein SasG in biofilm formation by Staphylococcus aureus. J Bacteriol. 2010;192(21):5663-5673. doi:10.1128/JB.00628-10

3. Santajit S, Indrawattana N. Mechanisms of antimicrobial resistance in ESKAPE pathogens. Biomed Res Int. 2016;2016:1-8. doi:10.1155/ 2016/2475067

4. Liu GY. Molecular pathogenesis of Staphylococcus aureus infection. Pediatr Res. 2009;65(5 Pt 2):71R-77R. doi:10.1203/PDR.0b0 $13 \mathrm{e} 31819 \mathrm{dc} 44 \mathrm{~d}$

5. Honda H, Krauss MJ, Coopersmith CM, et al. Staphylococcus aureus nasal colonization and subsequent infection in intensive care unit patients: does methicillin resistance matter? Infect Control Hosp Epidemiol. 2010;31(6):584-591. doi:10.1086/652530

6. Otter J, French G. Community-associated meticillin-resistant Staphylococcus aureus strains as a cause of healthcare-associated infection. $J$ Hosp Infect. 2011;79(3):189-193. doi:10.1016/j. jhin.2011.04.028

7. Khairalla AS, Wasfi R, Ashour HM. Carriage frequency, phenotypic, and genotypic characteristics of methicillin-resistant Staphylococcus aureus isolated from dental health-care personnel, patients, and environment. Sci Rep. 2017;7(1):1-16. doi:10.1038/s41598-01707713-8

8. Leonard AC, Petrie LE, Cox G. Bacterial anti-adhesives: inhibition of Staphylococcus aureus nasal colonization. ACS Infect Dis. 2019;5 (10):1668-1681. doi:10.1021/acsinfecdis.9b00193

9. Bornstein E. Eradication of Staphylococcus aureus and MRSA in the nares: a historical perspective of the ecological niche, with suggestions for future therapy considerations. Adv Microbiol. 2017;7 (06):420. doi:10.4236/aim.2017.76034

10. Gurusamy KS, Koti R, Toon CD, Wilson P, Davidson BR. Antibiotic therapy for the treatment of methicillin-resistant Staphylococcus aureus (MRSA) in non surgical wounds. Cochrane Database Syst Rev. 2013;11.

11. Murchan S, Kaufmann ME, Deplano A, et al. Harmonization of pulsed-field gel electrophoresis protocols for epidemiological typing of strains of methicillin-resistant Staphylococcus aureus: a single approach developed by consensus in 10 European laboratories and its application for tracing the spread of related strains. J Clin Microbiol. 2003;41 (4):1574-1585. doi:10.1128/jcm.41.4.1574-1585.2003
12. Harmsen D, Claus H, Witte W, et al. Typing of methicillin-resistant Staphylococcus aureus in a university hospital setting by using novel software for spa repeat determination and database management. J Clin Microbiol. 2003;41(12):5442-5448. doi:10.1128/ JCM.41.12.5442-5448.2003

13. Hallin M, Friedrich AW, Struelens MJ. spa typing for epidemiological surveillance of Staphylococcus aureus. In: Molecular Epidemiology of Microorganisms. Springer; 2009:189-202.

14. Vázquez-Sánchez D, López-Cabo M, Saá-Ibusquiza P, RodríguezHerrera JJ. Incidence and characterization of Staphylococcus aureus in fishery products marketed in Galicia (Northwest Spain). Int J Food Microbiol. 2012;157(2):286-296. doi:10.1016/j.ijfoodmicro.2012.05.021

15. Güler I, Kılı̧ H, Atalay MA, Percin D, Erçal BD. Genotyping of nosocomial methicillin-resistant Staphylococcus aureus strains isolated from clinical specimens by rep-PCR. Mikrobiyol Bul. 2011;45(4):581-591.

16. Enright MC, Day NP, Davies CE, Peacock SJ, Spratt BG. Multilocus sequence typing for characterization of methicillin-resistant and methicillin-susceptible clones of Staphylococcus aureus. J Clin Microbiol. 2000;38(3):1008-1015. doi:10.1128/JCM.38.3.1008-1015.2000

17. Maiden MC, Bygraves JA, Feil E, et al. Multilocus sequence typing: a portable approach to the identification of clones within populations of pathogenic microorganisms. Proc Natl Acad Sci. 1998;95 (6):3140-3145. doi:10.1073/pnas.95.6.3140

18. O'Toole GA. Microtiter dish biofilm formation assay. J Vis Exp. 2011;30(47):2437.

19. Diep BA, Gill SR, Chang RF, et al. Complete genome sequence of USA300, an epidemic clone of community-acquired meticillin-resistant Staphylococcus aureus. Lancet. 2006;367 (9512):731-739. doi:10.1016/S0140-6736(06)68231-7

20. Gad GFM, Aziz AAA, AlyIbrahem R. In-vitro adhesion of Staphylococcus spp. to certain orthopedic biomaterials and expression of adhesion genes. $J$ Appl Pharm Sci. 2012;2(6):145.

21. Mathur T, Singhal S, Khan S, Upadhyay D, Fatma T, Rattan A. Detection of biofilm formation among the clinical isolates of staphylococci: an evaluation of three different screening methods. Indian J Med Microbiol. 2006;24(1):25. doi:10.4103/0255-0857.19890

22. Bauer A, Kirby W, Sherris JC, Turck M. Antibiotic susceptibility testing by a standardized single disk method. Am J Clin Pathol. 1966;45(4_ts):493-496. doi:10.1093/ajcp/45.4_ts.493

23. CLSI. Performance standards for antimicrobial susceptibility testing; twenty-sixth informational supplement. CLSI document M100-S24. Wayne, PA: Clinical and Laboratory Standards Insitute; 2016.

24. Ardakani MA, Ranjbar R. Molecular typing of uropathogenic E. coli strains by the ERIC-PCR method. Electron Physician. 2016;8 (4):2291-2296. doi:10.19082/2291

25. Wertheim HF, Melles DC, Vos MC, et al. The role of nasal carriage in Staphylococcus aureus infections. Lancet Infect Dis. 2005;5 (12):751-762. doi:10.1016/S1473-3099(05)70295-4

26. Shenoy ES, Paras ML, Noubary F, Walensky RP, Hooper DC. Natural history of colonization with methicillin-resistant Staphylococcus aureus (MRSA) and vancomycin-resistant Enterococcus (VRE): a systematic review. BMC Infect Dis. 2014;14(1):177. doi:10.1186/ 1471-2334-14-177

27. Alzoubi HM, Aqel AA, Al-Sarayreh SA, Al-Zayadneh E. Methicillinresistant Staphylococcus aureus nasal carriage among primary school-aged children from Jordan: prevalence, antibiotic resistance and molecular characteristics. J Egypt Public Health Assoc. 2014;89 (3):114-118. doi:10.1097/01.EPX.0000454671.83406.e8

28. Ellis MW, Hospenthal DR, Dooley DP, Gray PJ, Murray CK. Natural history of community-acquired methicillin-resistant Staphylococcus aureus colonization and infection in soldiers. Clin Infect Dis. 2004;39 (7):971-979. doi:10.1086/423965

29. Altınbas A, Shorbagi A, Ascioglu S, Zarakolu P, Cetinkaya-Sardan Y. Risk factors for intensive care unit acquired nasal colonization of MRSA and its impact on MRSA infection. J Clin Lab Anal. 2013;27 (5):412-417. doi:10.1002/jcla.21620 
30. El-Mahdy TS, Al-Agamy MH, Emara M, Barakat A, Goering RV. Complex clonal diversity of Staphylococcus aureus nasal colonization among community personnel, healthcare workers, and clinical students in the Eastern Province, Saudi Arabia. Biomed Res Int. 2018;2018:1-9. doi:10.1155/2018/4208762

31. Kishore S, Verma D, Siddique M. Comparison of in-vitro activities of linezolid and vancomycin against Staphylococcus aureus isolated from a tertiary care hospital. J Clin Diagn Res. 2014;8(5):DC12DC15. doi:10.7860/JCDR/2014/7751.4338

32. Rajaduraipandi K, Mani K, Panneerselvam K, Mani M, Bhaskar M, Manikandan P. Prevalence and antimicrobial susceptibility pattern of methicillin resistant Staphylococcus aureus: a multicentre study. Indian J Med Microbiol. 2006;24(1):34. doi:10.4103/0255-0857.19892

33. Ardic N, Ozyurt M, Sareyyupoglu B, Haznedaroglu T. Investigation of erythromycin and tetracycline resistance genes in methicillin-resistant staphylococci. Int J Antimicrob Agents. 2005;26 (3):213-218. doi:10.1016/j.ijantimicag.2005.06.013

34. Vandendriessche S, Kadlec K, Schwarz S, Denis O. Methicillinsusceptible Staphylococcus aureus ST398-t571 harbouring the macrolide-lincosamide-streptogramin B resistance gene erm (T) in Belgian hospitals. J Antimicrob Chemother. 2011;66(11):2455-2459. doi:10.1093/jac/dkr348

35. Baddour MM, Abuelkheir MM, Fatani AJ. Trends in antibiotic susceptibility patterns and epidemiology of MRSA isolates from several hospitals in Riyadh, Saudi Arabia. Ann Clin Microbiol Antimicrob. 2006;5(1):1-11. doi:10.1186/1476-0711-5-30

36. Bukharie HA, Abdelhadi MS. The epidemiology of methicillin-resistant Staphylococcus aureus at a Saudi university hospital. Microb Drug Resist. 2001;7(4):413-416. doi:10.1089/ 10766290152773428

37. Panhotra BR, Saxena AK, Al Mulhim AS. Prevalence of methicillin-resistant and methicillin-sensitive Staphylococcus aureus nasal colonization among patients at the time of admission to the hospital. Ann Saudi Med. 2005;25(4):304-308. doi:10.5144/02564947.2005.304

38. Zhou W, Shan W, Ma X, et al. Molecular characterization of rifampicin-resistant Staphylococcus aureus isolates in a Chinese teaching hospital from Anhui, China. BMC Microbiol. 2012;12 (1):1-5. doi:10.1186/1471-2180-12-240

39. Hung W-C, Chen H-J, Lin Y-T, et al. Skin commensal staphylococci may act as reservoir for fusidic acid resistance genes. PLoS One. 2015;10(11):e0143106. doi:10.1371/journal.pone.0143106

40. Fung SK, Louie M, Simor AE. Combined topical and oral antimicrobial therapy for the eradication of methicillin-resistant Staphylococcus aureus (MRSA) colonization in hospitalized patients. Can J Infect Dis Med Microbiol. 2002;13(5):287-292.

41. Cavalcanti AB, Goncalves AR, Almeida CS, Bugano DD, Silva E, Teicoplanin versus vancomycin for proven or suspected infection. Cochrane Database Syst Rev. 2010;6:Cd007022. doi:10.1002/ 14651858.CD007022.pub2

42. Miyazaki M, Nagata N, Miyazaki H, et al. Linezolid minimum inhibitory concentration (MIC) creep in methicillin-resistant Staphylococcus aureus (MRSA) clinical isolates at a single Japanese center. Biol Pharm Bull. 2014;37(4):679-682. doi:10.1248/bpb.b13-00670
43. Clemett D, Markham A. Linezolid. Drugs. 2000;59(4):815-827. doi:10.2165/00003495-200059040-00007

44. Lakhundi S, Zhang K. Methicillin-resistant Staphylococcus aureus: molecular characterization, evolution, and epidemiology. Clin Microbiol Rev. 2018;31(4):e00020-e00018.

45. Aanensen DM, Spratt BG. The multilocus sequence typing network: mlst. net. Nucleic Acids Res. 2005;33(suppl_2):W728-W733. doi:10.1093/nar/gki415

46. Kosek M, Yori PP, Gilman RH, et al. Facilitated molecular typing of Shigella isolates using ERIC-PCR. Am J Trop Med Hyg. 2012;86 (6):1018-1025. doi:10.4269/ajtmh.2012.11-0671

47. Lim S, Lee D-H, Kwak W, et al. Comparative genomic analysis of Staphylococcus aureus FORC_001 and S. aureus MRSA252 reveals the characteristics of antibiotic resistance and virulence factors for human infection. J Microbiol Biotechnol. 2015;25(1):98-108. doi:10.4014/jmb.1410.10005

48. Bowers JR, Driebe EM, Albrecht V, et al. Improved subtyping of Staphylococcus aureus clonal complex 8 strains based on whole-genome phylogenetic analysis. Msphere. 2018;3(3). doi:10.1128/mSphere.00464-17

49. Elzorkany KM, Elbrolosy AM, Salem EH. Methicillin-resistant staphylococcus aureus carriage in hemodialysis vicinity: prevalence and decolonization approach. Indian $J$ Nephrol. 2019;29(4):282. doi:10.4103/ijn.IJN_56_18

50. Stegger Á, Andersen P, Kearns A, et al. Rapid detection, differentiation and typing of methicillin-resistant Staphylococcus aureus harbouring either mecA or the new mecA homologue mecALGA251. Clin Microbiol Infect. 2012;18(4):395-400. doi:10.1111/j.14690691.2011.03715.x

51. Paterson GK, Harrison EM, Holmes MA. The emergence of mecC methicillin-resistant Staphylococcus aureus. Trends Microbiol. 2014;22(1):42-47. doi:10.1016/j.tim.2013.11.003

52. Morales G, Picazo JJ, Baos E, et al. Resistance to linezolid is mediated by the cfr gene in the first report of an outbreak of linezolid-resistant Staphylococcus aureus. Clin Infect Dis. 2010;50 (6):821-825. doi:10.1086/650574

53. Bhatta DR, Cavaco LM, Nath G, et al. Association of Panton Valentine Leukocidin (PVL) genes with methicillin resistant Staphylococcus aureus (MRSA) in Western Nepal: a matter of concern for community infections (a hospital based prospective study). BMC Infect Dis. 2016;16(1):1-6. doi:10.1186/s12879-016-1531-1

54. Ansari S, Nepal HP, Gautam R, et al. Threat of drug resistant Staphylococcus aureus to health in Nepal. BMC Infect Dis. 2014;14 (1):157. doi:10.1186/1471-2334-14-157

55. Lindgren A-K, Nilsson AC, Åkesson P, Gustafsson E, Melander E. Eradication of methicillin-resistant Staphylococcus aureus (MRSA) throat carriage: a randomised trial comparing topical treatment with rifampicin-based systemic therapy. Int J Antimicrob Agents. 2018;51 (4):642-645. doi:10.1016/j.ijantimicag.2017.08.021 


\section{Publish your work in this journal}

Infection and Drug Resistance is an international, peer-reviewed openaccess journal that focuses on the optimal treatment of infection (bacterial, fungal and viral) and the development and institution of preventive strategies to minimize the development and spread of resistance. The journal is specifically concerned with the epidemiology of antibiotic resistance and the mechanisms of resistance development and diffusion in both hospitals and the community. The manuscript management system is completely online and includes a very quick and fair peerreview system, which is all easy to use. Visit http://www.dovepress.com/ testimonials.php to read real quotes from published authors. 